of Aesthetics $(21 ; 2019$; Belgrade) Possible worlds of contemporary aesthetics: aesthetics between history, geography and media [Elektronskiizvor] : proceedings / 21st International Congress of Aesthetics ICA 2019, Belgrade, 2019. - Belgrade : University of Belgrade, Faculty of Architecture, 2019 (Belgrade : GrafikCentar). (CD-ROM) ; $12 \mathrm{~cm}$ - pp. 1042-1046.

DOI 10.15826/B978-5-7996-3081-2.50

\title{
Art \& Science Potential in the Development of Russian Scientific Communication in the Museum Exhibition Policy Context
}

\section{Yarmosh Anastasia Sergeevna}

St. Petersburg State University, St. Petersburg, Russia a.yarmosh@spbu.ru

Abstract: Art projects are usually expected to have the form of dual communication. Now we can see growing interest in the modern practice of technological art in Russia. The key aspect of the human-oriented models development is seen in the results of scientific and technological development actualization through the complex objects of art \& science. This is proved by the example of the interdisciplinary project "ChaosMeasure: science as a way of communication".

Keywords: exhibition project, media environment, modern museum, scientific communication, technological art

\section{Introduction}

Today, we can state a century of technological art development in Russia in the context of a changing historical picture, political discourse, and world concepts. Some examples of technological (scientific) art in Russia of the twentieth century were interpreted in the study of the practices of the avant-garde, underground and nonconformism, contemporary art of the turn of the XX-XXI centuries. At the same time, there was so little attempts to consider technological (scientific) art as an original phenom- 
enon, to explore its semantic boundaries, artistic qualities, strategies, and socio-cultural role in the development of such a phenomenon as scientific communication.

Modern forms of communication practices in art \& science projects of cultural and artistic orientation are interactive and meet the high requirements of immersion, which allows museums and scientific institutions to involve a wide range of recipients and visitors in their processes. Art projects are often expected to have a form of two-way communication, in contrast to declarative or didactic variations of classical and contemporary art. In this regard, in the environment of the technological art project it is not easy to make the formation and correction of public opinion and individual insinuations in the field of non-verbal communication on certain issues.

In this context, we can draw attention to the growing interest in the technological art (the field of Art \& Science - Bioart, RoboticsArt, Neuroart, $\mathrm{AI}+$ art, etc.) in modern exhibition activities in Russia. Over the past years have been regularly held exhibitions, art and competition projects based on the technological capabilities of modern science. It should be noted that projects such as "Innovation as a method in art" (Saint Petersburg, 2018) and "Daemons in the Machine" (Moscow, 2018), which were relevant and had a wide resonance, went beyond the borders of cultural capitals. In 2018-2019, we note similar artistic initiatives in Perm, Ekaterinburg, and Vladivostok ("New state of life", Perm, 2019; "New anthropology", Koltushi, 2019, and others). This growing popularity of technological art is currently reflected in the cultural policy of many regions of the Russian Federation, and as a result, requires a meaningful analysis not only from the point of view of art institutions, but also from the point of view of forming an objective view of the development of science and technology in society, which the scientific communication is responsible for.

The second key aspect lies in the development of human-oriented models in various manifestations of public policy and, in particular, terms of updating the results of scientific and technological development in Russia. Dynamic and continuously updated information about the current development of high science and technology are already included in the cultural context of our time. The development of digital culture and the transfer of locus agendi to the virtual digital environment actually call into question the relevance of the national identity and cultural integrity criteria and blurs the boundaries of acceptable verbal and non-verbal communication practices in modern 
Russian society. Contextualization of these phenomena through the prism of art projects (exhibitions, competitions) should be reflected in the strategies of visual, verbal and mediative communication of contemporary art projects and art \& science initiatives in Russia. Creating a human-oriented environment in modern innovative scientific and cultural centers is a priority goal of the current agenda and is focused on the development of scientific, educational and socially significant areas in Russia and internationally.

In this regard, it is necessary to analyze the existing strategies of cultural and museum communication in technological art projects: to investigate both, assessing the communicative and immersive possibilities of involving different groups of recipients (in order to avoid the development of cultural exclusion zones (age, level of education, inclusive aspect)), and creating conditions for forming a reliable idea of the nature of high-tech phenomena and science. However, for explicating art \& science projects, it is necessary to analyze the stereotypes and prejudices about science as a human reaction to new conditions of its existence in the context of high-tech activities results.

Such an assessment will create an information environment for modern cultural policy in Russia, which includes development and popularization of science and high technologies. The experience of meaningful dialogue within art \& science projects will strengthen two-way communication using visual means of technological art, reduce the risks of information distortion, the emergence of zones of cultural, digital or technological exclusion, and as a result, prevent cultural conflicts.

\section{Main part}

\subsection{The subject}

The focus of the researchstudy are art \& science projects presented in the period from 2019 to the present at exhibition project "ChaosMeasure: science as a way of communication". They are media objects with a different range of basic areas of natural science knowledge and technologies-biology, genetics, quantum physics, and others. Individual examples of technological art in this case may have two or more basic technologies, be formulated in the context of different discursive components, and correspond to several specific strategies in the field of scientific communication. In this case, the methods and properties of the rhizome will be applied to them in the research of objects in artistic practice that are syncretic in nature. 
Comparison of the objects, combined with analysis of institutional critique, public opinion, and the evolution of the genre, will reveal the specific features and situational characteristics of the individual phases of objects' representation and the interaction with them in the viewer. The study of the communicative significance of the interaction between the recipient and the object in technological art in the case under study will identify and update potential communicative and social risks in the development of modern art culture in contact with Art \& Science practice.

\subsection{Methodology and methods of research}

The corpus of scientific methods is defined by the research strategy. Taking into account the fundamental importance of studying the communicative potential of Art \& Science, analysis of its content and characteristics of the cross-section of public opinion, expert opinion of professional groups, the key for this project are:

- situational analysis (case-study) with the identification and analysis of the case of a directly implemented exhibition and art project, and related situations of ethical, cultural or aesthetic conflicts, the response ("resonance") of society to the proposed communication solutions;

- content analysis, for the purpose of subject study and analysis of the content of explications of technological art projects selected for research. Content analysis of this group of materials will allow you to compare and identify specific features, similarities, and differences in the content of documentation describing the strategy and direction of development of exhibition and exhibition activities related to technological art. It will also be possible to observe and specify the direction/directions of development of such projects, determine the characteristic technological forms of project implementation, the most popular methods of communication practices and mediation in their implementation, which influence the formation of public opinion;

- in-depth interviews, in order to obtain an objective opinion and assess the current communication strategies, conflicts of various types that arise on the sites during the implementation of exhibition and competition projects in the field of art \& science. An in-depth interview was conducted with the curators of the scientific, exhibition and exhibition parts of the "ChaosMeasure: science as a means of communication" project. The interview results will allow the establishment of metrics, including a description of marker traits in the focus groups, individual recipients, focused on projects 
and exhibitions of technological art in Russia, to define strategic goals and principles of museum communication in the implementation of projects of technological art; to identify groups of recipients, conditional cultural alienation is excluded from the curatorial strategies to localize the definition of the role of science and technology in the components of communicative strategies.

Among the research methods, traditionally characterized research in the field of art history is assumed to refer to fundamental concepts for the proposed study are definitely the previously mentioned "rhizome" (Deleuze, Guattari), and the concept of the simulacrum (Baudrillard) and the whole mythologizing of contemporary culture by R. Barth. Taking into account the versatility of technological art, it is hypothetically assumed to follow the method of comparative research based on strictly formulated metrics. Various characteristics will serve as the boundaries of research metrics. Firstly, the technological basis of the phenomenon (art object, installation, performance, etc.), namely the natural science base for creating an object (wave theory, sound, optical technologies, synthetic biology, digital technologies, neurotechnologies, artificial intelligence, etc.). Differentiation by basic technology will allow one to analyze the nature of artistic communication in the process of the viewer's dialogue with Art \& Science objects and describe variations in strategies and dependence on the technological component. Secondly, to construct the metrics the strict attention should be payed to the degree of the language universality and the desire to overcome the stable fragmentation. This is more typical for the culture of postmodern (Foucault), then for the technological art. The universality of the language of modern science and high technologies determines the high degree of homogeneity of phenomena in technological, and wider Art \& Science. Comparison by metrics, combined with analysis of institutional criticism, public opinion, and the evolution of the genre itself, will reveal specific features that have remained present over a long period of study, and historical-specific features that are characteristic of individual stages of cultural development. In the latter case, it is possible to refer to the basic principles of the historical and cultural method.

\subsection{Description of the research}

One of the factors that determine the nature of social processes in the modern digital economy is the use of the results of scientific research and high-tech developments in the humanities, including artistic fields. 
In this sense, Art \& Science projects (including technological art), obviously react on the interaction of science, man and society in the field of artistic practice. At the same time, without emphasizing direct economic effects of certain scientific discoveries and technologies, art projects based on these technologies, using them, strive to preserve the primacy of basic humanistic values and actualize issues of the ethical spectrum. Such contradictions, for example, were noticed during early experiments on noise extraction in the 1920s by practitioners of the Russian avant-garde and Italian futurists (Druskin), and later in the development of contemporary art in the second half of the twentieth century.

Practice of technological art, which affects such actors as the viewer, society, and modern (digital) culture, becomes the most specific object for monitoring the development of communication practices and strategies in the existing modern culture. Analysis of this practice gives the modern researcher an understanding of the current development direction and a certain field for foresight decisions.

This problem attracted great attention in the research of the twentieth century and, given the complex nature of the phenomenon sought, is considered within the framework of various aspects and scientific traditions in the field of art theory, philosophy, and STS. In general terms, the specifics and socio-cultural consequences of scientific and technological progress are described by the classics of the globalization theory (Beck, Huntington). The most important principles of research on the impact of digital technologies on modern society were laid down by M. McLuhan. The philosophy of digital culture becomes the subject of theoretical discourse and the theory of new media (Heim, Erwit, Swan, Manovich). In general, the research interest of the 1990s-2010's is still focused on the consideration of certain aspects of the relationship between art and technology, where technology is defined as the dominant force in the dynamics of socio-cultural processes (Wilson, Paul, Rinehart and Heylis).

Technological art and its manifestations are interpreted in the context of research on the philosophy of digital culture in the practice of Russian researchers - V. Kutyrev, T. Martirosyan, V. Rozin, N. Mankovskaya, D. Galkin. The works of T. Adorno had a significant impact on research in the field of transformation of ideas of humanism under the influence of the development of technology. The problem of the significance of technology development is revealed in the complex of the philosophical heritage of postmod- 
ernism by V. Benjamin, J. Baudrillard, J. Liotard, and P. Virilio, which forms the theoretical basis for studying the relationship between technology and society and their impact on culture and art in the years 1970-1990. Individual works of researchers such as D. Bulatov, D. Galkin, J. Hauser, L. Beloff, and R. Blessing focus on defining strategies for contemporary art, including certain aspects of Art \& Science theory.

Several types of convergent relations are developing in the digital culture: man-man, including through the mediation of digital tools, man-machine and machine-machine. In a certain sense, these dual pairs work in the context of modern technological art as part of the communication process between the creator, the object, and the recipient (viewer). In this dialogue, one of the key roles is played by understanding the technology, the technological chain, or the involved high-tech solution that underlies the author's message. In many cases, we register the need to understand the scientific component in order to verify the author's idea (S. Jonson, T. Schubert, etc.). In this regard, the statement that the face of modern technologies determines the substrata of modern culture, including art, is not unfounded and affects socio-cultural contexts. The nature of this dialogue is also changing due to the involvement of people in virtual consumption. In this sense, the virtual space created by the aura of a contemporary art object is part of a postmodern turn in culture and an organic part of it that actively flirts with the category of simulacra. The other side of these communication processes is the blurring of the lines between man and machine, since in the digital paradigm there is no functional difference between a signal coming from a machine and a human agent. Appealing to the object in the conflict, the viewer associates it with the dialog agent, with the "live" vis-a-vis in this dialogue, to the artist, while the grain of the conflict may lie a literal distance defined by the inability to comprehend the essence of the technological basis on which the concept of an artistic object is built (N. Wiener). Thus, the source of conflicts in the new technological environment and in the conditions of digital culture is the ambiguity of the recipient's (viewer's) ideas about the nature and form of interaction with the field of high technologies through an art object. Taking into account the fundamentally different goal setting of these relationships, the range of interspecific conflicts that arise during conditional "communication" is quite wide and occurs against the background of adjusting the strategies of modern art under the influence of a rapidly changing scientific picture of the world. 
Currently, with the existing hyperbolization of the relationship between a person and a technological solution (for example, digital or robotic), there is an understanding that the solution of communication practices is no longer limited by the rules of Isaac Asimov. Humanistic value, as a derivative that arises from a meaningful encounter with an art object, in this case is transformed under the influence of the conditions, opportunities and boundaries of a new form of interaction - immersive, interactive, digital. Digital environments and media that differ in the qualities of immersiveness and convergence form a fundamentally new meta-language of communication and, as a result, are cited in the strategies of modern technological art.

In this regard, the study of phenomena originating from the early practice of technical figurative arts and their inheriting of technological artistic practices and strategies of modern art in the field of Art \& Science, which do not have a precedent/casual basis, but are based on a deep analysis of the phenomenon, taking into account the trends in the evolution of modern science and digital culture, is an urgent issue of modern complex research in the field of art and scientific communication.

The interdisciplinary exhibition project "ChaosMeasure: science as a way of communication" was selected as a project relevant to two areas: modern research interest - Scientific Communication and Art \& Science. The exhibition part of the project included art objects by media artists: Olaf Schirm, Natalia Alfutova, IBIOM group, Vladlena Gromova and Artem Paramonov, Egor Kraft, Natalia Fedorova, Marta de Mendes, Paul Vanuz, 18apples group, Anais Tondor, Elena Nikonole, Vasily Sumin. Turning to the representation of the artistic process and experience at the intersection of art and science, the curators included in the project a wide range of sections of science and art media: from robotics (the Melt object is an Autonomous robotic projection device) and digital technologies ("Content Aware Studies", Egor Kraft) to ornithology ("Language of Birds", Elena Nikonole) and biotechnologies (“AntiMarta//I’m”, Marta de Mendes; "LABOR”, Paul Vanuz; "MetabolA.I”, Ippolit Markelov). The works selected by the curators illustrate the thematic tracks of the exhibition project - "Art \& Science today", "Life Forms", "Non-Life Forms", "Quantum in Art". It should be noted that the curatorial text contains a reference to the scope of the project - " the exhibition does not claim to cover a wide range of issues in the field of Art\&Science, but is a cross-section of current practices and an illustration of the most significant, in our opinion, topics." The main discourse of "ChaosMeasure" 
is obviously in the plane of discussion, which forms and makes relevant in the current agenda the main points of the institutional and interdisciplinary interpenetration of the fields of scientific knowledge and the metaphorical language of art. In this way, artistic practices related to technology are becoming another, now less familiar, platform for public discussion about creating a life-oriented humane environment in the era of technological change.

\section{Results and their interpretation}

As part of the research, an open interview was conducted for visitors of the interdisciplinary exhibition project "ChaosMeasure: science as a means of communication". The interview was conducted as part of the exhibition program at the St. Petersburg communications museum in February 2020. The core of the respondents (over $50 \%$ ) was a group of museum visitors aged 18-24 years, students and graduates of higher educational institutions. The three main questions of the survey metric were addressed to the study of expectations from the form and method of communication (dialogue) built between the viewer and objects of technological art. For example, when asked about the preferred form of organizing a museum visit along with traditional independent visits $(43.5 \%)$, respondents pointed to the advantages of mediation (14.1\%) and conversations/meetings with the artist (37.1\%). It is obvious that building a two-way effective communication with an object that has a strong scientific and technical medium required more explanations for the viewer than the existing explication. The increasing role of the mediator ("translator" and "facilitator") in the modern practice of exhibition activity is mentioned by J. Falk, where he points out the increasing role of social and psycho-emotional connections between the viewer (visitor) and the object in the process of "Museum travel", which is based on the help of a "guide" [Falk, 2006, 156-157]. The answers to the question related to the expectation of greater interactivity and involvement of the subject of communication in the processes of a conditional museum in the future also appeal to this. Thus, the majority of respondents, describing the basic features of the "museum of the future", pointed to the need for "involvement with the presented object, i. e., direct participation, not observation of the fence", "interactivity, which allows you to make a trip to the museum emotionally filled and memorable" and "inclusion, interactivity, multi-functionality" (hereafter, spelling, punctuation, style of the author are preserved). It is interesting to note that only one out of 65 respondents mentions the inclusion, which may indicate that there is still a low 
culture and widespread experience in interacting with inclusive formats and programs when implementing exhibition projects. In the field of technological art, the socially applicable norms of the inclusion have some limitations. On the other hand, the widespread use of digital media in the creation of art objects, on the contrary, expands the possibilities of inclusive programs through technological metaphor and flexibility in the art objects presentation.

The problem of so-called technological or digital inequality has a certain specificity, the signs of which have recently become more common in the assessments of Art \& Science projects among non-professional visitors. By its nature, it belongs to the field of information ethics, where the problems of digital inequality are considered. Capurro, the director of the International center for information ethics, notes that this is not only a "problem of technical access", but also raises a number of issues in connection with new digital interactive formats that create "the danger of exploitation, leveling, colonialism and discrimination in the sphere of culture". An open information society, in his view, requires taking into account the properties of hybrid communication, "delineating new contours of freedom and peace in a society that is increasingly determined by the influence of digital technologies" [Capurro, 2010, 12].

In this context, it is interesting to quote one of the respondents of the ChaosMeasure exhibition, concerning the description of the viewer's feeling in the space of the curator's technological and artistic context: "visitors feel that they have come to a foreign territory, that they do not belong there, or they feel that they cannot understand and need an explanation. People need to be given accessible tools so that they can independently discover art and feel "on an equal footing" with the exhibition." Such technological and medial alienation/exclusion in curatorial practice was the focus of the exhibition "Technology as Context" (2014), where curators Alan Liedts and Isolde de Buck looked at current art and already traditional media through the prism of new technologies. The medium of programmed communication for them was to introduce objects and images of "both art and scientific discoveries and innovative technologies", which in general allowed the viewer to "change the ways of thinking and understanding the world" [Lidts and de Buk, 2014, 12]. At the same time, the main object of perception here remained technology and its contextual capabilities. In the project "ChaosMeasure: science as a way of communication", curators take a step towards understanding, making scientific communication not a subject of curatorial research, but a way of orga- 
nizing the process of knowledge - "Art \& Science is an area where the most modern scientific and technological developments are critically interpreted, and therefore it is there that we can see the border of cognoscibility. The challenges that the further development of artificial intelligence, the prospects of quantum technologies, the reinterpretation of the concept of man under the pressure of the latest developments in the field of biotechnology-these and other issues are raised by artists in the works selected for the exhibition" [curatorial text, O. Remneva, L. Savina, 2019]. An integral part of this project is a public and educational program where artists, Art \& Science researchers, scientists and mediators literally build communication tracks for the viewer with the field of interspecific dialogues in nature, quantum physics, and digital technologies. The participation of representatives of various professional communities, including academic ones, creates an environment of trustful communication for visitors to the ChaosMeasure exhibition.

\section{Conclusions}

In modern museum and exhibition activities, there is obviously an interest in hybridization and thematic fusion of various objects of museum design. Previously accepted conventional norms and ideas about "scientific" and "art" museums remain inapplicable in cases where the basis of dialogue (communication) about the current scientific agenda and innovative high technologies is the explication of objects of technological art. The nature of this communication is twofold, as it forces the curator to explain himself in two professional languages at once-the metaphor of art and the language of science. In this regard, an important task in building strategies for cultural and Museum communication in technological art projects is to assess the communicative and immersive capabilities of viewers. Involving different groups of recipients in the scientific discourse through Art \& Science objects requires taking into account age parameters, educational level, and the inclusive aspect in order to avoid the development of cultural exclusion zones. It should be taken into account that the appeal to Art \& Science, from the point of view of creating conditions for the formation of a reliable understanding of the nature of high-tech phenomena of science, requires a meaningful construction of a mediation program and the popularization of scientific knowledge. Meanwhile, this art direction can be a representative basis for building a dialogue between society and representatives of the scientific environment in the context of the current technological agenda, digital 
culture and the culture of the future. Due to the mixture of technology and art in objects of Art \& Science, the society understands deeply the aspirations and movements of modern science.

\title{
References:
}

1. J.H. Falk. An Identity-Centered Approach to Understanding Museum Learning. Curator, 49 (2) (2006). pp. 151-166.

2. R. Kapurro. Informatsionnaya etika. Informatsionnoye obshchestvo [Information ethics. Information society]. \#5 (2010). pp. 6-15.

3. A. Liedts, I. de Buck. Technology as Context. Expand the scope contemporary artistic creations and traditional media by employing new technologies. LiedtsMeesen Foundation Publ., Ghent (2014).

DOI 10.15826/B978-5-7996-3081-2.51

\section{The Role of a Mediator in the Participatory Practices in the Museum (Mediation and Facilitated Discussion)}

\author{
Melnikova Svetlana' ${ }^{\text {, Zhuravleva Nadezhda }}{ }^{\text {, }}$ \\ Bulatova Anastasiya ${ }^{3}$ \\ 1 Ural Federal University, Ekaterinburg, Russia \\ 2 Ural Federal University, Ekaterinburg, Russia \\ ${ }^{3}$ Ural Federal University, Ekaterinburg, Russia \\ Corresponding author: Melnikova Svetlana, meln-svetlana@mail.ru
}

Abstract: In the era of the participation culture "viewer-inclusive" methods of communication in the museum have become in demand almost everywhere. The authors pose a question to the master of such a communication practices role. Analyzing participatory practices in terms of the achieved results, the authors appeal to the experience of art mediation (D. Malikova, E. Kochukhov, M. Lind, C. Mörsh), the VTC method (A. Housen, P. Yenawine) and its version adapted for Russian students - facilitated discussion (N. V. Ievleva, M. V. Potapova). The master of participatory practices acts as a part of an art environment. The master determines the perception and description norms for an art object, 